\title{
El ejercicio de los derechos sexuales y reproductivos: un estudio cualitativo de personas heterosexuales con VIH en México
}

\author{
Lourdes Campero, M Ed, ${ }^{(1)}$ Tamil Kendall, M en A, ${ }^{(2)}$ Marta Caballero, DCS, ${ }^{(3)}$ \\ Ana Lorena Mena, M en C, ${ }^{(4)}$ Cristina Herrera, DCS. ${ }^{(3)}$
}

\section{Campero L, Kendall T, Caballero M, Mena AL, Herrera C. El ejercicio de los derechos sexuales y reproductivos: un estudio cualitativo de personas heterosexuales con VIH en México. Salud Publica Mex 2010;52:6I-69.}

\begin{abstract}
Resumen
Objetivo. Analizar experiencias relacionadas con el ejercicio de los derechos sexuales y reproductivos de personas heterosexuales que viven con VIH (PVVIH) en México. Material y métodos. Estudio cualitativo donde se realizaron 40 entrevistas en profundidad a PVVIH en cuatro estados del país. Resultados. Vivir con VIH sin apoyo ni consejería limita el ejercicio de los derechos sexuales y reproductivos, especialmente en las mujeres. Las principales limitantes son sentimientos de frustración, falta de claridad en la información, temor a la reinfección, falta de poder para negociar el uso del condón, estigma, discriminación y falta de acceso a servicios y tecnología adecuados. Conclusión. Para una mayor conciencia y ejercicio de los derechos de las PVVIH se necesita promover la educación sexual, cambios culturales que combatan la desigualdad de género, el estigma y la discriminación, e información oportuna y científica sobre prevención del $\mathrm{VIH}$.
\end{abstract}

Palabras clave: VIH/SIDA; derechos sexuales y reproductivos; género; derechos humanos; México

\author{
Campero L, Kendall T, Caballero M, Mena AL, Herrera C. \\ Exercising sexual and reproductive rights: \\ a qualitative study of heterosexual people \\ with HIV in Mexico. \\ Salud Publica Mex 2010;52:6I-69.
}

\begin{abstract}
Objective.To analyze experiences of heterosexual Mexican people living with HIV (PLWHA) related to the exercise of their sexual and reproductive rights. Material and Methods. Qualitative study based on 40 in-depth interviews with PLWHA in four Mexican States. Results. Lack of support and counseling limits the exercise of sexual and reproductive rights by PLWHA, especially women. Principal limitations include feelings of frustration and confusion, fear of re-infection, scanty information, lack of power to negotiate condom use, social stigma and discrimination, and limited access to services and adequate technologies. Conclusion. To increase awareness and exercise of rights by PLWHA it is necessary to: improve sexual education; promote processes of cultural change to combat gender inequality and stigma and discrimination; and provide timely and scientific information about HIV prevention.
\end{abstract}

Key words:HIVIAIDS; sexual and reproductive rights; gender; human rights; Mexico

(I) Centro de Investigación en Salud Poblacional. Instituto Nacional de Salud Pública. Cuernavaca, Morelos, México.

(2) Universidad de la Columbia Británica (UBC-Okanagan). Kelowna, British Columbia, Canada.

(3) Centro de Investigación en Sistemas de Salud. Instituto Nacional de Salud Pública. Cuernavaca, Morelos, México

(4) Servicios de Salud del Estado de Durango. Durango, México.

Fecha de recibido: 2 de junio de 2008 - Fecha de aceptado: 18 de noviembre de 2009

Solicitud de sobretiros:Tamil Kendall. I502 Stanley St., Nelson, British Columbia, Canada.

Correo electrónico: tamilhiv@gmail.com 
$\mathrm{V}$ ivir con VIH no debe excluir a las personas del ejercicio de sus derechos humanos fundamentales, entre los que se encuentran los derechos sexuales y reproductivos. Algunos de ellos son la libertad y respeto a la opción de la reproducción y al ejercicio de la sexualidad; la libertad de decidir el número de hijos y el espaciamiento entre ellos; la elección de métodos anticonceptivos o proconceptivos; el derecho a recibir información clara, oportuna y científica acerca de la sexualidad; el derecho a servicios de salud adecuados y a disponer de opciones con mínimo riesgo; y el derecho a recibir protección ante la amenaza o violación de los derechos sexuales y reproductivos. Cualquier violación a estos derechos atenta contra los marcos legislativos nacionales y convenciones internacionales, ${ }^{1-4}$ así como contra varios criterios de atención establecidos en la Norma Oficial Mexicana para la Prevención y Control de la Infección por Virus de la Inmunodeficiencia Humana NOM-010-SSA2-1993 y $2000 .{ }^{5}$

Si bien los marcos jurídicos de los derechos son bastante claros, existen obstáculos o dificultades para llevar a cabo lo estipulado en las normas legales, ya sea porque no hay mecanismos previstos para ello, porque éstos no son efectivos, o porque persisten creencias, actitudes o comportamientos que impiden su cumplimiento. ${ }^{6}$

Los derechos sexuales y reproductivos no se modifican en una persona por estar infectada por VIH, como tampoco se modifican, en muchos casos, las motivaciones y prácticas reproductivas y sexuales. Harris encuentra que las personas que viven con VIH (PVVIH) experimentan su sexualidad de manera similar a las personas seronegativas, ${ }^{7}$ y en un estudio con 1421 PVVIH en edad reproductiva observa que $28 \%$ de los hombres y $29 \%$ de las mujeres que recibían atención médica manifestaban deseos de tener hijos en el futuro. ${ }^{8}$ En otro estudio con mujeres VIH positivas en México, la organización pro derechos reproductivos de las mujeres Ipas encontró que cuando las mujeres desean evitar un embarazo se debe principalmente al temor de tener hijos infectados, al deseo de concentrar sus recursos en mejorar su propia salud, o bien al hecho de tener el número de niños que desean. ${ }^{9}$ Uno de los pocos trabajos en Latinoamérica que hace referencia a las aspiraciones reproductivas de los hombres que viven con VIH indica que éstos manifiestan las mismas razones que los hombres seronegativos para tener hijos: el de formar una familia, o bien, tener un hijo para sentirse más hombres. Entre las razones para no tener más hijos se encuentran la paridad satisfecha, la edad, la situación económica, el saberse seropositivo, y el miedo de infectar al niño/a. ${ }^{10}$

ONUSIDA estimó que para 2008 habría en México 200000 personas con VIH. ${ }^{11}$ Las estadísticas nacionales señalan que desde el inicio de la epidemia hasta noviembre del 2007 se diagnosticaron y notificaron 115 651 casos de sida. Datos recientes indican que de 1995 al 2006 se han infectado con el virus de la inmunodeficiencia humana 37797 personas, de las cuales 81.6\% corresponden a hombres y $16 \%$ a mujeres en edad reproductiva. ${ }^{12}$ Estas cifras nos hablan de un importante número de personas infectadas.

En este trabajo nos abocamos a identificar y describir las necesidades, aspiraciones y experiencias sexuales y reproductivas de hombres y mujeres con VIH, y a analizar algunos aspectos comunes así como diferencias por género, que desde su propia experiencia influyen en el ejercicio o no de sus derechos. Este artículo no retoma todos los derechos sexuales y reproductivos a los que una persona puede aspirar y exigir, sino que rescata y analiza, a partir de las narraciones de los entrevistados, aquéllos que de manera directa o indirecta aluden a experiencias sujetas a su posible ejercicio o a un distanciamiento de ellos. En particular, hacemos énfasis en el acceso a información, a los servicios de salud, a condiciones de equidad de género y libertad que son necesarias para poder ejercer los derechos sexuales y reproductivos. Si bien la sexualidad comprende los aspectos tanto biológicos como psicológicos y sociales que permiten al ser humano el intercambio afectivo y erótico con otra(s) persona(s) o consigo mismo, en este trabajo nos referiremos particularmente a las implicaciones del ejercicio de la sexualidad que se experimenta con una pareja heterosexual que puede incluir o no un vínculo amoroso.

\section{Material y métodos}

El presente trabajo forma parte de un estudio cualitativo más amplio cuyo objetivo fue conocer las experiencias y necesidades particulares por género de las personas con VIH, así como la dinámica del apoyo social que recibían bajo esta condición. El protocolo del estudio fue revisado, comentado y aprobado por las comisiones de Investigación, Bioseguridad y Ética del Instituto Nacional de Salud Pública de México.

La muestra estuvo constituida por 20 hombres y 20 mujeres mayores de 18 años, con diagnóstico VIH positivo desde un año antes o más, que se autorreconocían como heterosexuales, se encontraban en estado ambulatorio en el momento del estudio (2003-2004), y que tenían contacto con grupos de autoayuda en Morelos, Guerrero, el Distrito Federal y el Estado de México (cuadro I). Todos los participantes con estas características fueron invitados y su colaboración fue voluntaria. En nuestra selección quisimos mostrar una variedad de contextos sociales de vulnerabilidad en relación con el 
Cuadro I

Características sociodemográficas de personas heterosexuales con VIH. MéXICo, 2003-2004

$\begin{array}{cccc}\text { Variables } & \text { Mujeres } & \text { Hombres } & \text { Total } \\ N=20 & N=20 & N=40\end{array}$

\begin{tabular}{|c|c|c|c|}
\hline \multicolumn{4}{|l|}{ Edad } \\
\hline $26-35$ & 5 & 7 & 12 \\
\hline $36-45$ & 10 & 8 & 18 \\
\hline 46 o más & 5 & 5 & 10 \\
\hline
\end{tabular}

Educación

Algunos años de primaria o analfabeta

\begin{tabular}{lccc}
\hline Primaria & 9 & 4 & 13 \\
\hline Secundaria/técnica & 5 & 8 & 13 \\
\hline Preparatoria & 4 & 3 & 7 \\
\hline Universidad & 1 & 3 & 4 \\
\hline No específica & --- & 1 & 1
\end{tabular}

Estado civil

\begin{tabular}{lrrr} 
Casado/a & 4 & 1 & 5 \\
\hline Separado/a - divorciado/a & 4 & 5 & 9 \\
\hline Viudo/a & 8 & 3 & 11 \\
\hline Segunda unión o casamiento & 4 & 4 & 8 \\
\hline Soltero/a & --- & 7 & 7
\end{tabular}

Número de hijos

Ninguno

\begin{tabular}{lrrr}
\hline Menores de 18 años & -- & 13 & 13 \\
\hline Menores y mayores de 18 años & 5 & 3 & 13 \\
\hline Mayores de 18 años & 5 & 2 & 7 \\
\hline
\end{tabular}

\begin{tabular}{lccc}
$\begin{array}{l}\text { Cohabitación } \\
\text { Vive solo/a }\end{array}$ & --- & 3 & 3 \\
\hline Con hijos y sus parejas & 6 & 4 & 10 \\
\hline Con los hijos & 5 & --- & 5 \\
\hline $\begin{array}{l}\text { Con hijos y otros familiares } \\
\text { (suegros) }\end{array}$ & 9 & 2 & 11 \\
\hline Con familiares & --- & 9 & 9 \\
\hline Otros & --- & 2 & 2
\end{tabular}

Empleo

\begin{tabular}{lrrr} 
Sí & 7 & 10 & 17 \\
\hline No & 13 & 10 & 23
\end{tabular}

Seguridad social médica

\begin{tabular}{lrrr} 
Sí & 12 & 7 & 19 \\
\hline No & 8 & 13 & 21
\end{tabular}

Tiempo de Dx

\begin{tabular}{lrrr}
$1-3$ años & 5 & 9 & 14 \\
\hline $4-7$ años & 10 & 9 & 19 \\
\hline Más de 7 años & 5 & 2 & 7
\end{tabular}

Tratamiento

\begin{tabular}{lrrr} 
Sí & 18 & 16 & 34 \\
\hline No & 2 & 4 & 6 \\
\hline
\end{tabular}

VIH con el propósito de mostrar experiencias comunes y diferencias entre hombres y mujeres de diferentes edades, situaciones familiares y contextos sociales. Alo largo del proceso de recolección de información fue posible observar que el punto de saturación teórica era alcanzado en los temas de mayor interés para el estudio. ${ }^{13}$

Como instrumento para recopilar la información se utilizó una guía de entrevista cuyo objetivo fue motivar la narración libre del informante sobre sus propias experiencias en cuanto al impacto del VIH/sida en su vida, abordando entre ellas su vida sexual y reproductiva. Las entrevistas fueron conducidas por investigadoras y profesionistas de las ciencias sociales, capacitadas y con larga experiencia no sólo en el tema de las PVVIH sino en metodología y técnicas cualitativas. Las entrevistas se realizaron en lugares que permitieron garantizar la privacidad de los informantes (ONG, consultorios médicos desocupados o su propio domicilio) según cada uno/a eligiera. El diálogo quedó registrado en su totalidad (con previa autorización de los participantes) en audiograbación, y fue transcrito en procesador de palabras. Como guía teórica para el análisis de la información se rescataron elementos del interaccionismo-simbólico y de la teoría fundamentada, retomando la dimensión del sentido subjetivo de la acción social y de la interacción entre los actores, en función del significado que tienen para ellos. ${ }^{14}$ También el enfoque de género resultó fundamental para nuestro análisis, en tanto creemos que las acciones y significados que las personas dan a sus experiencias -especialmente tratándose de la sexualidad y los derechos relacionados con ésta- están fuertemente condicionados por las construcciones sociales y normativas sobre el género.

El procedimiento analítico fue inductivo, usando elementos de la teoría fundamentada a través del método propuesto por Glaser y Strauss ${ }^{15}$ para organizar la información por temas, con base en códigos. Estos fueron revisados y ajustados, así como sus definiciones originales. Este procedimiento sirvió para desarrollar un esquema temático de clasificación y organización del material de campo. En Herrera y Campero se encuentra una descripción más detallada sobre el método que se utilizó para el análisis de la información del presente estudio. ${ }^{16-17}$ Para este trabajo se priorizó el análisis de la información vinculada con el ejercicio de la sexualidad, la prevención, el uso de métodos anticonceptivos y la reproducción. La información se procesó en el paquete de análisis ATLAS/TI 4.2.*

* Muhr T. Scientific Software Development. Visual Qualitative Data Version. ATLAS Ti 4.2. PC / Windows 95. Berlin: Scolari Sage Publications Software, 1997. 


\section{Resultados}

Los resultados de este estudio están organizados en tres temas centrales con el objetivo de analizar a partir de éstos las posibilidades de ejercicio de los derechos y las decisiones que los acompañan: el ejercicio de la sexualidad con una pareja antes del diagnóstico, el ejercicio de la sexualidad después del diagnóstico, y el comportamiento reproductivo. En este trabajo únicamente nos referiremos a las relaciones heterosexuales que los informantes reportaron. Las características sociodemográficas de lo participantes se presentan en el cuadro I.

\section{El ejercicio de la sexualidad con una pareja antes del diagnóstico}

No es extraño identificar entre los testimonios de los y las participantes el hecho de que aún antes de su diagnóstico seropositivo las PVVIH no ejercían (parcial o totalmente) sus derechos sexuales y reproductivos. En el caso de las mujeres, esto es vivido de manera más frecuente y en un mayor número de circunstancias.

A excepción de un caso, todos los informantes del estudio se infectaron por vía sexual, y entre las razones que mencionan como motivo de la infección aparece una falta de claridad sobre los riesgos que conlleva el sexo no protegido (en concreto, la adquisición del VIH). Esta carencia, vista desde el contexto de los derechos ciudadanos, se relaciona con una violación o no protección del derecho a información veraz y oportuna.

"La verdad no había información, nunca se hablaba de eso en mi familia y cuando estaba de soldado incluso se enojaban cuando decían VIH. Es algo prohibido en el ejército" (Tobías).

La negociación del uso del condón en las relaciones sexuales es también un evento muy poco presente en las historias narradas. La desigualdad entre los géneros $y$, por tanto, el escaso poder de las mujeres en la relación de pareja, es una condición que acompaña esta situación. La vulnerabilidad social de las mujeres se refuerza cuando ellas no acceden al conocimiento de sus derechos y menos aun a su ejercicio. En el ámbito del ejercicio de la sexualidad con una pareja se manifiesta en la aceptación o, incluso, la obligación mediante la violencia de tener relaciones sexuales no deseadas, la mayor parte de las veces sin protección.

“...porque yo casi con él ya no teníamos relaciones, cuando teníamos, cómo le dijera, era cuando él llegaba borracho y que él me agarraba a la fuerza" (Adela).
Así los embarazos no deseados también fueron narrados como una muestra del no ejercicio de sus derechos reproductivos, y a veces inclusive de imposiciones culturales y sociales:

“...tuve a mis tres hijos no deseados; tuve un niño que amo con todo mi corazón, a los demás también los amo, pero ése fue un niño deseado, era mi obligación tenerlos" (Ema).

\section{El ejercicio de la sexualidad con una pareja después del diagnóstico}

El ejercicio de la sexualidad con una pareja después de un diagnóstico seropositivo es complejo y está rodeado por experiencias variadas y con condicionantes muy particulares debidos a la misma situación de vivir con VIH. Se organizarán estas experiencias en dos subgrupos: A) el de aquéllos que deciden renunciar al ejercicio de su sexualidad en una relación de pareja, aunque sea temporalmente y B) el de aquéllos que siguen ejerciendo el derecho a una vida sexual en pareja.

La renuncia, aunque sea temporalmente, al ejercicio de la sexualidad en una relación de pareja posdiagnóstico

Algunas personas optaron por "dejar como dormida esa parte de su cuerpo" que relacionan con la transmisión del virus. El rechazo a la sexualidad es mayormente expresado por las mujeres entrevistadas y se entremezcla con sentimientos de coraje y frustración. En algunos casos, la renuncia, que se concretiza en abstinencia sexual, es parte de un libre ejercicio de los derechos sexuales; no obstante, y particularmente en el caso de las mujeres, es consecuencia del rechazo a condiciones poco favorables para una vida sexual "satisfactoria y sin riesgos", lo cual forma parte de un estereotipo cultural en donde la experiencia sexual individual es una obligación para la mujer y un placer para el hombre.

"R: Se terminó todo sexualmente P: ¿Y eso por qué fue? $R$ : Porque es como si yo, siempre me digo, bueno, si ya él me echó a perder o él me contagió por el sexo, ¿por qué debo de estar aceptando más sexo?" (Ema).

Hay casos en que las relaciones sexuales son vistas como una obligación de la vida en pareja, no como un deseo; por ello, en las "complicaciones" que puede ocasionar vivir con $\mathrm{VIH}$, las mujeres encuentran buenas razones para evadir el ejercicio de la sexualidad.

"No. Con él no he tenido relaciones, porque te digo, tengo ese miedo [...] Yo tengo esa desconfianza para 
tener relaciones, más que nada porque te digo, nunca las he disfrutado, y digo no, pues para qué voy a... No, no tengo ese deseo de tener relaciones, y sí me lo ha pedido, pero me da miedo tener relaciones con él, y ahora, yo quería terminar con él" (Beny).

Por otro lado, si bien la familia es para varios de los informantes una fuente de apoyo, un soporte económico y/o afectivo, y un apoyo en el seguimiento del tratamiento y/o de la dieta, para otros tiene un papel controlador. Si las mujeres viven de por sí una mayor supervisión social y cultural por parte de familiares y allegados, en el momento en que se sabe que tienen la infección sienten que requieren de la autorización familiar para el ejercicio de su sexualidad, como se demuestra en la siguiente afirmación:

"Si yo viviera así sola, pues sería diferente. Pero si estoy ahí, ellos me apoyan, tampoco yo puedo fallarles [teniendo o buscando otra pareja]" (Adolfa).

En ocasiones, debido a que ellas viven en la casa de sus padres o suegros, tienen el temor de que si ellos no están de acuerdo y son "descubiertas", puedan perder el apoyo que reciben y hasta ser expulsadas de esos hogares.

"Pues realmente yo pensé mucho para tener una relación. Tenía miedo que me fueran a ver, o me fueran a decir: 'Te vi'. Temor a que le dijeran a mi suegra, a mi suegro, digo. Yo vivo en la casa de ellos, al rato me van a correr de la casa, ese es el miedo que yo tenía" (Laura).

Otros dos temas presentes entre los y las entrevistadas/os son la posibilidad de la reinfección (infección con virus mutado o de otra familia viral de la pareja sexual) y la dificultad para negociar el sexo protegido, lo que, aún después del diagnóstico, los hace estar en guardia o tener actitudes de cautela. Algunas veces, aun cuando desearan ejercer su vida sexual con un compañero/a, el temor al manejo de la relación y a la reinfección los y las detiene. Mientras varios expresan ciertos conocimientos en torno a la prevención de la reinfección, hay quien no tiene muy claro cómo se da el proceso o en qué consiste:

"Sí, me darían ganas de tener relaciones, pero a la vez me da temor de que lo vaya yo a infectar. Me dicen en los estudios que sale indetectable, pero no sé. Lo tengo todavía, ¿no? He oído que dicen mis compañeros que hay esa reinfección ¿no? No sé tampoco de eso, es lo que yo quisiera que nos explicaran, de cómo te puedes reinfectar" (Beny).
Este desconocimiento y las dificultades para negociar el preservativo, en particular en el caso de las mujeres, provoca en algunas la idea de que es mejor ya no tener relaciones sexuales. Martina, como otras mujeres entrevistadas, habla de sus miedos a una reinfección y nunca menciona el condón como alternativa. Ella explica que no ha tenido relaciones y no quiere tener pareja:

“Tengo miedo. Yo me he sentido bien de salud, pero sí he escuchado de las re-infecciones, de reinfectarse, así que mejor no" (Martina).

La dificultad en la negociación del uso del condón acrecienta esta misma situación, sobre todo entre las mujeres:

"A mí me cuesta mucho trabajo porque como no puedo así tan fácil decir: 'Ay, sí me voy a acostar con fulano, zutano y ya me pongo mi condón, ok. Pero pues como que no, yo no puedo ser así" (Luz).

Otro temor de las personas con VIH es que aquellos con quienes se involucren emocionalmente no respeten su confidencialidad, lo que puede ocasionarles en sus círculos inmediatos la estigmatización por ser seropositivos, especialmente si la relación no perdura. Esto les impide vincularse emocional y sexualmente con otros/as.

"En un noviazgo, o una cosa así, le tendría que decir, pues, lo que está pasando conmigo [que es seropositivo], y al mismo tiempo, me da miedo porque como ella [la persona con la que quiere involucrarse] es vecina, si no me acepta, más va a meter el terror [en el barrio]" (Edmundo).

Por último, pero no por eso menos importante, las personas entrevistadas expresan el temor a infectar a la otra persona si tienen relaciones sexuales con ella y, para algunos, esta inseguridad se experimenta aun pensando en una relación con condón. Hay quien categóricamente manifiesta que su temor o dolor es tan grande, que prefiere no tener ninguna pareja sexual.

“Es algo que duele mucho [el diagnóstico] y pues hasta la fecha yo no, todavía no he podido sacar toda esa espinita que me ha estado dañando porque no me gustaría lastimar a alguien, herir a alguien sin querer, no me gustaría que esa persona sufra lo que yo sufrí, sienta lo que yo sentí ¿por qué? Porque la persona que a mí me hizo esto sabía lo que tenía y nunca me dijo, pero yo no soy capaz de hacerlo" (Daniel). 


\section{El ejercicio de la sexualidad con una pareja posdiagnóstico}

Una vez que las PVVIH conocen su diagnóstico, pueden modificar o no sus prácticas sexuales y con esto su nivel de riesgo. Las experiencias sexuales pueden ser múltiples; no obstante, aquí mencionaremos algunos casos referentes al ejercicio de los derechos bajo ciertas prácticas de riesgo, y otros con un mayor control del posible riesgo. Las personas entrevistadas que dicen que continuaron teniendo vida sexual después del diagnóstico expresan que esto ocurrió tanto con su pareja anterior al diagnóstico como con parejas nuevas.

Ejercicio de la sexualidad con menos riesgo: el uso el condón

Después del diagnóstico, varios de los entrevistados mencionaron que fueron médicos especializados, psicólogos, y / o compañeros de grupo de apoyo quienes les explicaron cómo debían cuidarse adecuadamente para prevenir riesgos al tener relaciones sexuales. Es evidente que en muchos de estos casos, tanto los proveedores de salud como los compañeros lograron con sus argumentos transmitir seguridad para ejercer la sexualidad con menor riesgo.

“Nos platicaban de cómo prevenir. A mí en lo personal todo eso me han explicado y creo que yo tengo mucha información. Yo sé cómo se debe usar [el condón], cómo ponérselo, por qué se rompe o por qué no se rompe, o sea, toda esa información he tenido. Entonces supuestamente lo óptimo es saber ponérselo y usar lubricantes" (Edmundo).

Esto ocurre cuando las PVVIH logran participar en un grupo; se hace evidente la contribución que éstos dan al reconocimiento y apropiación de sus derechos sexuales y reproductivos.

"Nos han hablado [en el hospital y el grupo] de que nosotras debemos de llevar una vida normal porque somos iguales. Nos han dicho que nosotros tenemos derecho a disfrutar de una relación sexual, siempre y cuando sea con responsabilidad" (Carmen).

Hay una diferencia significativa en el uso del condón entre la experiencia de los varones respecto de la de las mujeres (nos referimos al condón masculino porque es el de uso más frecuente). Al tener la decisión en sus manos, los hombres ejercen más libremente su sexualidad con una pareja porque tienen la seguridad de que si ellos quieren, pueden protegerse o proteger a su compañera usando el condón. En muchos de los testimonios de los varones entrevistados se identifica la decisión de ellos como un hecho, sin "piedras" en el camino.

"Pues uno de hombre se busca una mujer y se protege, la protege a ella.Y la mujer no, la mujer tiene que acercarse a un varón y hablarle, o a su enamorado, quien sea ¿no? Entonces, pues es difícil [para una mujer] decirle: 'Sabes qué, ponte protección, ¿no?'" (Manuel).

Los testimonios de las mujeres evidencian que la decisión de usar el condón tiene que pasar por procesos intermedios para poder consumarse. Por ejemplo, ante una pareja nueva, una mujer que no quiera revelar su estatus de seropositiva de entrada tiene que buscar formas de protegerse y proteger al otro, justificando su proposición de usar condón con argumentos "más legítimos"; de otra manera, puede generar dudas o sospechas. La confianza y la posibilidad de embarazo o de otras enfermedades aparecen como tema de negociación sexual:

“P: ¿Te da miedo?, ¿por qué? R: De que me vaya a rechazar pero si lo protejo, yo sé cuáles son, cómo se trasmite y todo. Sí sé cómo es el sexo seguro. P: ¿Cómo negocias la protección, no te cuesta trabajo que se ponga el condón? $R$ : Yo le digo que yo ahorita no deseo salir embarazada, o por alguna enfermedad. Así me lo llevo ahí" (Cleta).

En algunos casos este proceso de negociación finalmente logra su cometido, pero en otros, el hombre se niega a usar el condón, como se verá en el siguiente apartado.

Ejercicio de la sexualidad con una pareja sin protección

Son diversos los argumentos de los entrevistados para no utilizar protección sexual. En primer lugar, el condón está muy relacionado con relaciones esporádicas, fortuitas y sin compromiso afectivo, por lo que al pasar a tener una pareja "estable" es común que deje de usarse. Como se ha evidenciado en diversos estudios, particularmente las mujeres, incluyendo las seropositivas, tienen mayores barreras culturales para la negociación del condón.

"Porque no me van a querer así, a ese muchacho que te digo que conocí, pues me gusta mucho, me atrae demasiado, sé que también le gusto. Ya estuvimos juntos una vez, y al principio yo le dije que con el preservativo ¿no?, y aceptó pero fueron dos, tres veces y que no, o sea, no le gusta, que no quiere, que porque es como ponerse una 
bolsa y que no se siente nada, y pues la cosa es que lo hicimos sin preservativo, y yo estoy así de que me siento muy mal, tengo un sentimiento de culpa de tener que verlo, porque lo estaba viendo a diario" (Rosaura).

Este testimonio ilustra la complejidad que supone la búsqueda del respeto de los derechos sexuales y reproductivos en contextos sociales caracterizados por la inequidad de género y el estigma relacionado con el VIH. Como Cleta, Rosaura buscó proteger a su pareja sexual a través del uso del condón, pero sin revelar su diagnóstico, por miedo al rechazo. Tuvo éxito y luego fracasó por su escaso poder en las negociaciones sexuales. En el momento de la entrevista estaba aterrada ante la idea de que se supiera que vive con $\mathrm{VIH}$, porque su compañero sexual y los hermanos de éste tenían antecedentes de violencia en la comunidad y ella temía por su integridad física si revelaba su estatus.

Aun cuando ambos miembros de la pareja sexual vivan con $\mathrm{VIH}$, el sexo no protegido presenta riesgos a la salud (reinfección, otras infecciones de transmisión sexual), pero no es raro encontrar parejas que llegan a valorar no usar ninguna protección, debido a la asociación del condón con relaciones no afectivas:

"Lo que pasa es que también con mi ex esposa [también positiva], dijimos: bueno un condón no nos va a separar, vamos a seguir teniendo relaciones sin el preservativo, aunque teníamos idea de lo que era la reinfección, pero pues dijimos: bueno, pues si vamos a vivir un año o diez años o cincuenta años, vamos a vivirlos bien ¿no?" (Edmundo).

En otras circunstancias, el no uso del condón se relaciona con su costo y / o su poca disponibilidad en los servicios de salud, particularmente cuando las personas carecen de suficientes recursos económicos.

"Y luego no hay condones en los centros de salud, y ni que uno tenga mucho dinero para estar comprando condones en farmacias" (Juanita).

\section{El comportamiento reproductivo}

Algunos de los entrevistados mencionaron tener satisfecha su paridad, es decir, haber tenido los hijos que deseaban tener. Otros, por el contrario, expresaron su deseo de tener uno o más hijos. No obstante, prácticamente todos ellos identificaron impedimentos para lograrlo. Por un lado, expresaron que la información sobre el procedimiento para tener hijos sin VIH no es suficientemente clara:
“Pero información para tener un hijo así que nos la den detalladamente como debe ser, nunca, hasta la fecha no nos han dado" (Tobías).

Aun cuando cuenten con cierta información, sólo unos cuantos creen que podrían tener acceso a procesos seguros.

"R: Sé que yo podría embarazar a una mujer sin que yo le infectara, en el caso de que ella no se hubiera defendido, así le llaman al lavado de esperma, a todo eso, y que también el niño salga sin el VIH. P:¿Y ella? [se refiere a la pareja] ¿Estuvo embarazada alguna vez? R: ¡No! Nunca, decidimos no tener hijos, por lo mismo de la enfermedad, podrían nacer ellos con el virus, luego pensábamos, cuando llegue el momento de que nos vayamos, ¿a quién se los vamos a dejar, cómo va a ser la cosa?, o sea, ¿para qué traer hijos así?" (Edmundo).

Si bien este entrevistado tenía un nivel de información más alto que el promedio de los informantes, seguía expresando miedo a la posibilidad de morir y dejar un hijo huérfano. Es claro que a menor información, mayor temor a infectar a su pareja y menor claridad sobre cómo tener hijos sin VIH. En el caso de los hombres, muchos expresaron privarse de la paternidad debido a falta de información veraz sobre este tema o, incluso, a consejos del personal de salud que desalentaban estas prácticas en ellos por tener VIH. Por ejemplo, la psicóloga de un hospital, que además conducía el grupo de autoapoyo para personas seropositivas, consideraba al deseo de tener hijos en estas personas como un "deseo neurótico" y, en consecuencia, orientaba su consejería hacia ellos a través de estos preconceptos.

Finalmente, es importante señalar que aun cuando existen importantes limitaciones y consecuencias para ejercer sus derechos reproductivos, son varios los hombres y mujeres entrevistados que expresaron deseos de tener hijos.

"Por eso no me hago ilusiones, porque de ganas no me faltan, pero ahorita ya me empezaron a explicar, ya me dijo un doctor que sí se puede una embarazar, que solamente que estés indetectable del virus, pero yo me pongo a pensar, digo, si yo soy indetectable y mi pareja no, y yo lo infecto o... pero ganas sí tengo" (Cleta).

"Guardo la esperanza de formar una familia. Bueno, la ventaja es que sé que si tengo que quitarme el preservativo, no es seguro en un 100\% que ella se puede infectar, por eso hago ejercicio, siempre manejo mis cargas virales abajo, pero sé que de 10 hijos de padres infectados, antes, 
dos tenían la posibilidad de ser sanos y ahora ya aumentó mucho, 6 sin seropositividad" (Celeste).

Son pocos los que llegan a pensar, aunque sea difusamente, en la posibilidad de la adopción para satisfacer el deseo de ser padres y madres.

\section{Discusión}

Este trabajo muestra el contexto en el cual las PVVIH en México pueden ejercer sus derechos sexuales y reproductivos. A lo largo del trabajo se pudo identificar que las PVVIH experimentan las mismas necesidades sexuales y reproductivas que las personas seronegativas; no obstante, la búsqueda de la satisfacción de éstas se ve modificada por las diversas barreras que tienen que vencer por el hecho de vivir con $\mathrm{VIH}$, y más aun si carecen de apoyo social. En términos generales, existen en ellos mayores temores e inseguridades (infectar a su pareja, reinfectarse ellos mismos y / o tener un embarazo y por tanto un hijo infectado, o bien, el desamparo de los hijos si llegaran a faltar ellos como padres y cuidadores); también existe el desconocimiento (hay mayor incertidumbre sobre si están haciendo o no lo correcto, si debieran o no usar condón cuando ya son VIH positivos, o cómo se da el proceso de reinfección); además hay alteración del estado emocional (se pueden sentir desmotivados para establecer relaciones sexuales y/o de pareja), y sentimientos como el enojo (por no haberse protegido antes). ${ }^{7-10}$

Las dificultades que estas personas mencionan se pueden convertir en razones para no ejercer su sexualidad con una pareja o satisfacer sus deseos reproductivos, y se puede observar que varias de éstas están centradas en prejuicios, estereotipos o prácticas discriminatorias, relacionadas con cuestiones de género, control de la familia y/o manejo de la confidencialidad para no ser estigmatizados/as. Pero también porque continúa presente, aun en las personas que viven con VIH, tanto la idea como la vivencia de que el condón es más un "estorbo" que una protección para disfrutar de un contacto sexual. Por otra parte, las debilidades y carencias en los sistemas de salud, las actitudes de ciertos proveedores de servicios, y la pobreza de muchas PVVIH, limitan no sólo el acceso a anticonceptivos sino también al condón masculino. Algo importante que resalta en este trabajo, al igual que en otros, ${ }^{18}$ es el hecho de que cuando las PVVIH logran recibir de sus compañeros de grupo y/o proveedores de salud información certera y clara, aumenta la seguridad en sus prácticas y es más factible para ellos adueñarse de sus derechos sexuales y reproductivos.
Vale la pena señalar que la información específica de prevención que proporcionan tanto el personal de salud como los grupos de apoyo para personas seropositivas se refiere particularmente a la necesidad de uso del condón en cualquier relación sexual. El condón se menciona como un método que evita la infección o la reinfección, pero llama la atención que difícilmente se hable del uso de otros métodos para ofrecer doble protección, en el caso de querer evitar embarazos no deseados.

Este trabajo hace explícita, una vez más, la necesidad no sólo de hablar del condón sino de trabajar con hombres y mujeres sobre estrategias de negociación del uso de métodos de protección en diferentes escenarios. Esta necesidad se hace más evidente cuando debido a la vulnerabilidad social no es posible revelar el diagnóstico a su/s pareja/s. Las inequidades sociales y, en particular, el poco poder en las negociaciones sexuales de las personas vulnerables (como las mujeres y muchas veces los hombres que tienen sexo con hombres y los usuarios de drogas), son motivos por los cuales ONUSIDA rechaza la criminalización de la transmisión del VIH como una medida de promover la salud publica. ${ }^{19}$

En este trabajo se trató el tema de los deseos de paternidad/maternidad de los participantes, pero también de sus decisiones respecto a no tener hijos, en este último caso, particularmente por falta de una garantía total de tener hijos saludables. A este respecto existe una importante controversia, ya que mientras algunos autores consideran que la reproducción (incluyendo la asistida) en una pareja con VIH debería ser considerada como una mala opción porque todavía existe la posibilidad de transmisión perinatal, ${ }^{20}$ otros expresan que actualmente, con atención adecuada (uso de antirretrovirales, cesárea programada y sustitución de leche materna) se puede reducir el riesgo de trasmisión hasta llegar 1 o 2\% y, por tanto, podría ser una opción para las PVVIH. ${ }^{21}$ Sin menospreciar esta discusión, que en definitiva es sumamente compleja, es necesario seguir diseminando información actualizada a las PVVIH ya que, como se aprecia en este trabajo, son muchas, particularmente las más jóvenes, las que desearían tener hijos. Por tanto, se requiere de información que permita tomar decisiones informadas y accesibilidad a procedimientos y servicios de salud que garanticen un mínimo riesgo de transmisión del virus. Los proveedores de salud, encargados de orientar a la población, deben estar capacitados para difundir este tipo de información y evitar sus prejuicios, particularmente cuando se trata de reproducción. En este trabajo, como en otros, ${ }^{22}$ se muestra la poca información y libertad que tiene una PVVIH para el ejercicio de este derecho. 
Es imprescindible promover la protección de los derechos sexuales y reproductivos para salvaguardar la dignidad humana, en este caso, de las personas que viven con VIH/sida. Para ello se debe proveer de información oportuna y científica sobre vías de transmisión y de prevención, promover la educación sexual y favorecer cambios culturales que combatan el estigma, la discriminación y la desigualdad de género. Se ha demostrado que cuando se protegen los derechos sexuales y reproductivos de las personas, el número de infecciones disminuye y se exige y promueve una atención más adecuada, lo que a su vez permite mejorar la salud pública de un país. ${ }^{23,24}$

\section{Referencias}

I. El Programa de Acción de la CIPD, párrafo 7.2 citado en UNFPA. Derechos, potenciación y desarrollo. [Consultado 2008 noviembre 4]. Disponible en: http://www.unfpa.org/swp/l997/spanish/sintro.pdf 2. Asamblea general. Declaración de compromiso en la lucha contra el VIH/SIDA. DF, 200I. [Consultado 2008 abril]. Disponible en: http://www. un.org/spanish/ag/sida/aress262.pdf

3. Convención sobre la eliminación de todas las formas de discriminación contra las mujeres. [Consultado 2008 noviembre 4]. Disponible en: http:// www.un.org/womenwatch/daw/cedaw/text/sconvention.htm 4. Gruskin S, Ferguson L, O'Malley J. Ensuring sexual and reproductive health for people living with HIV:An overview of key human rights, policy and health systems issues. Reprod Health Matters 2007; I5(S29): 4-26. 5. Norma Oficial Mexicana NOM-010-SSA2-1993, Para la prevención y control de la infección por Virus de la Inmunodeficiencia Humana para la Prevención del VIH/SIDA. Boletín de prensa \# 38. México, DF, 2000. [Consultado 2008 abril 18 ]. Disponible en:http://bibliotecas.salud. gob.mx/greenstone/collect/nomssa/index/assoc/HASHI Id2.dir/doc. pdf\#search="virus\%20de\%20la\%20inmunodeficiencia\%20humana" 6. Infante C, Zarco A, Cuadra SM, Morrison K, Caballero M, Bronfman M. El estigma asociado al VIH/SIDA: el caso del personal de salud en México. Salud Publica Mex 2006; 48(2): I4I-I50.

7.Williams HA, Watkins CE, Risby JA. Reproductive decision-making and determinants of contraceptive use in HIV-infected women. Clin Obstet Gynecol 1996; 39(2):333-343.

8. Chen JL, Phillips KA, Kanouse DE, Collins RL, Miu A. Fertility desires and intentions of HIV-positive men and women. Fam Plann Perspect 200I; 33(4): 144-152.

9. De Bruyn M. HIV/AIDS and Reproductive Health. Sensitive and neglected Issues. A review of the literature. Recommendation for action. Ipas, 2005. [Consultado 2008 noviembre 4]. Disponible en: http://www.ipas.org
10. Paiva V, Filipe EV, Santo N, Lima TN, Segurado A. The right to love: the desire for parenthood among men living with HIV. Reprod Health Matters 2003; I (22):9I- 100.

II. UNAIDS. Mexico Country Response. Fact Sheet. 2008.

[Consultado 2009 octubre]. Disponible en: http://www.unaids.org/en/ CountryResponses/Countries/Mexico.asp

12. Consejo Nacional para la prevención y control del VIH/SIDA. Panorama epidemiológico delVIH/SIDA e ITS en México. México, DF, 2007. [Consultado 2008 abril 18]. Disponible en: http://www.salud.gob.mx/ conasida/estadis/2007/diagnoynotificanoviembre.pdf

13. Bertaux D. Los relatos de la vida en el análisis social. En:AcevesLozano J, comp., Historia oral. México DF: Instituto de Investigaciones José María Luis Mora, 1993: I36-148.

14. Blumer H. Symbolic interactionism. Perspective and method. New Jersey: Prentice- Hall, Englewood Cliffs, 1969.

15. Glaser BG, Strauss AL. The Discovery of Grounded Theory. Strategies for qualitative research. New York:Aldine de Gruyter, 1967.

16. Herrera C, Campero L, Caballero M, Kendall T, Quiroz A. Cuerpo y sexualidad en la experiencia de vivir con VIH/SIDA: una exploración de diferencias y coincidencias de género en México. Estud Sociol 2009; 27 (79): 147- 170.

17. Campero L, Herrera C, Caballero M, Kendall T. Bridging the gap between antiretroviral access and adherence in Mexico: Results of a qualitative study/approach. Qual Health Res 2007; 17(5):599-6I I. I8. Bravo M, Dides C, Pérez S, Pascal R. Mujeres viviendo con VIH/SIDA. Diagnóstico sobre ética y derechos sexuales y reproductivos. Chile:Vivo Positivo, 2003.

19. UNAIDS. UNAIDS Policy Brief: Criminalization of HIV transmission, 2008. [Consultado 2008 octubre ]. Disponible en: http://data.unaids.org/ pub/BaseDocument/2008/2008073 I_jc|5 I3_policy_criminalization_en.pdf 20.Thornton A, Romanelli F, Pharm D, Collins JD. Review -Reproduction decision making for couples affected by HIV: A review of literature. Topics in HIV Medicine 2004; 12(2):6I-67.

2I.Volmink J, Siegfried NL,Van der Merwe L, Brocklehurst P. Antiretrovirals for reducing the risk of mother-to-child transmision of HIV infection. Cochrane Database of Syst Rev. 2006: [Consultado 2008 noviembre 4]. Disponible en: http://www.cochrane.org/reviews/en/ ab0035 I0.html

22. Pérez H,Taracena R, Magis C, Gayet C, Kendall T. Mujeres que viven con VIH/SIDA y servicios de salud. Recomendaciones para mejorar la calidad de la atención. México: Colección Ángulos del Sida, 2004. 23. Cook R, Dickens BM, Bernard M, Fathalla M. Salud reproductiva y derechos humanos: integración de la medicina, la ética y el derecho. Bogotá, Colombia: Oxford y Profamilia, 2003: 605

24. Instituto Interamericano de Derechos humanos. Derechos Humanos y VIH/SIDA: jurisprudencia del sistema interamericano y análisis comparativo del marco jurídico interno relativo al VIH/SIDA en los países centroamericanos. San José, Costa Rica:IIDH, 2000. 